\title{
Determination of current transport and trap states density in AlInGaN/GaN heterostructures
}

\author{
Engin Arslan ${ }^{\mathrm{a}, \mathrm{b}, *}$, Sertaç Ural ${ }^{\mathrm{b}}$, Şemsettin Altındal ${ }^{\mathrm{c}}$, Ekmel Özbay ${ }^{\mathrm{d}}$ \\ ${ }^{a}$ Department of Electrical and Electronics Engineering, Antalya Bilim University, 07190 Antalya, Turkey \\ ${ }^{\mathrm{b}}$ Nanotechnology Research Center - NANOTAM, Bilkent University, 06800 Ankara, Turkey \\ ${ }^{\mathrm{c}}$ Department of Physics, Faculty of Science, Gazi University, Teknikokullar, 06500 Ankara, Turkey \\ ${ }^{\mathrm{d}}$ Nanotechnology Research Center - NANOTAM, Department of Physics, Department of Electrical and Electronics Engineering, Bilkent University, 06800 Ankara, Turkey
}

\section{A R T I C L E I N F O}

\section{Keywords:}

Current-transport

Capacitance

Conductance

Trap states

AlInGaN alloy

Admittance

\begin{abstract}
A B S T R A C T
The energy distribution and the relaxation time constant of the trap states with respect to conduction bands in the (Ni/Au) Schottky contact on AlInGaN/GaN heterostructures were investigated using the admittance technique. The potential dependent capacitance/conductance measurements were done in the frequency range of $5 \mathrm{kHz}$ to $5 \mathrm{MHz}$ at a temperature of $300 \mathrm{~K}$. We found strong frequency dispersions at the accumulation regions and at the sharp transition regions (depletion region) in the capacitance curves. High frequency dispersion at the accumulation regions in $C-V$ characteristics indicates that there is a high-density of surface traps between the metal-AlInGaN quaternary layer interfaces. Furthermore, the frequency dispersion at the sharp transition regions behavior can be attributed to the interface traps state between the AlInGaN quaternary layer and GaN layer. A detailed analysis of the frequency-dependent capacitance and conductance data was performed, assuming the models in which traps are located between the metal-AlInGaN interface (surface traps) and between AlInGaN/GaN interfaces (interface traps). The trap states density and time constants of the traps states were calculated as a function of energy separation from the conduction-band edge. The trap states' densities change between $1.3 \times 10^{11} \mathrm{eV}^{-1} \mathrm{~cm}^{-2}$ and $6.2 \times 10^{11} \mathrm{eV}^{-1} \mathrm{~cm}^{-2}$. Also, 4.8 to $5.3 \mu$ s time interval calculated for the relaxation times.
\end{abstract}

\section{Introduction}

In the last decade, nitride-based wurtzite, such as ternary AlGaN, AlInN, and InGaN alloys as well as quaternary AlInGaN alloy, have gained considerable interest due to their potential for applications in many optoelectronic device structures such as high frequency and high power field effect transistor (FET), laser diodes (LD) and light emitting diodes (LED) devices [1-8].

Because of their superior properties compared to ternary alloys, the AlInGaN quaternary alloys have become the focus of interest among the other ternary alloys [3-8]. The independent control properties of the lattice constant and energy band gap, by varying the indium (In) and aluminum (Al) compositions of the AlInGaN alloys, provide additional freedom to adjust the strain and band gap, and make them attractive materials as active layers in visible and ultraviolet (UV) LED and LD [3,7-9]. Also, the spontaneous and piezoelectric polarization field in pseudomorphically grown AlInGaN quaternary alloys on a GaN template layer can be controlled by changing the In and $\mathrm{Al}$ composition.
This property applies important opportunity for the growth of the GaNbased heterostructures with high 2-dimensional electron density when it is used as a barrier layer [7-9]. Furthermore, the AlInGaN quaternary alloys can be grown lattice matched to GaN layer with an appropriate In and $\mathrm{Al}$ ratio, which reduces the defect and dislocation densities and might enhance device reliability [8,9]. Recently, GaN-based HEMT with an AlInGaN quaternary alloy barrier had been demonstrated with promising performance in comparison with AlGaN and AlInN barrier HEMT, which demonstrated the high potential of AlInGaN quaternary alloy in high-power, high-frequency applications $[6,8]$.

The electrical trap states in the GaN-based HEMTs change the density of the two-dimensional electron gas (2DEG) in the quantum well and, therefore, limit the performance of devices in operation mode [10-12]. The trapping/de-trapping process in HEMTs, currently place a major limitation on the power performance at high frequencies [10]. For this reason, the characterization and elimination of the trap states in the GaN-based HEMTs structures are important. There are several techniques being employed to measure and characterize the trap states

\footnotetext{
* Corresponding author at: Department of Electrical and Electronics Engineering, Antalya Bilim University, 07190 Antalya, Turkey.

E-mail address: engina@bilkent.edu.tr (E. Arslan).
} 


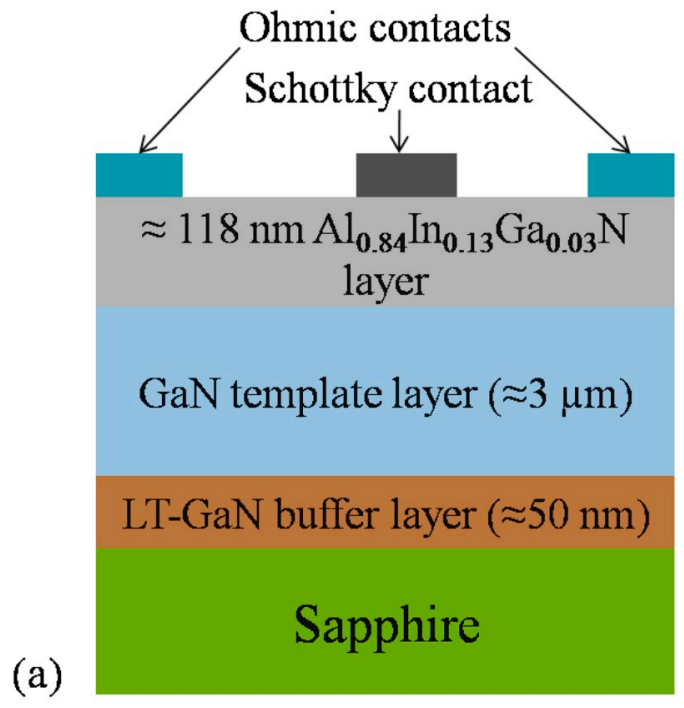

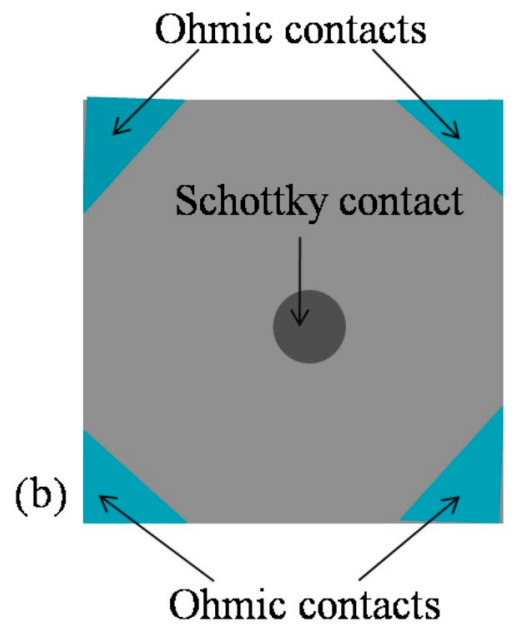

Fig. 1. (a) The schematic diagram of the present $\mathrm{Al}_{0.84} \mathrm{In}_{0.13} \mathrm{Ga}_{0.03} \mathrm{~N} / \mathrm{GaN}$ heterostructure grown on sapphire substrate with LT-GaN buffer and GaN template layer, (b) circular Schottky and square Van Der Pauw ohmic contact on the $\mathrm{Al}_{0.84} \mathrm{In}_{0.13} \mathrm{Ga}_{0.03} \mathrm{~N}$ epilayer surface.

in a metal-semiconductor (MS) and metal-oxide-semiconductor (MOS) structure [13,14]. The admittance method is one of the most sensitive and complete methods in the evaluation of the densities and relaxation times of the trap states $[13,14]$. This method is based on the frequency and voltage dependent capacitance and conductance measurements of an MS or MOS capacitor and the trap state densities and relaxation times, in both the depletion and weak inversion portion of the bandgap, the capture cross-section of the interface and the fluctuation of the surface potential can be calculated [11-23].

The number of studies has been reported in the literature about the identification and elimination methods of the trap states in the GaN layer [21], AlGaN/GaN [11,12,16,17,19,20,23,24] AlInN/GaN [18,22], and AlN/GaN [25] heterostructures using frequency-voltage dependent capacitance and conductance measurement. Zhu et al. [23] investigated the trap states in AlGaN/GaN Schottky-gate high-electron-mobility transistors (S-HEMTs) and $\mathrm{Al}_{2} \mathrm{O}_{3} / \mathrm{AlGaN} / \mathrm{GaN}$ metal-oxide-semiconductor HEMTs (MOS-HEMTs). They calculated $(1.02-4.67) \times 10^{13} \mathrm{eV}^{-1} \mathrm{~cm}^{-2}$ and $(0.09-0.12) \mu s$ for the density and time constant of surface states in S-HEMTs, respectively, and was concluded that electron tunneling rather than emission was considered to be the dominant de-trapping mechanism due to the high electric field in the high $\mathrm{Al}$ content barrier. Also, they reported that the $\mathrm{Al}_{2} \mathrm{O}_{3}$ gate insulator slightly reduced the surface states, but introduced a low density of new traps with the time constant of $(0.65-1.29) \mu$ s into MOSHEMTs.

Semra et al. [25] reported a study on trap states in researching the gate-source contact on AlGaN/GaN HEMT by performing capacitance and conductance measurements at a temperature between $83 \mathrm{~K}$ and $370 \mathrm{~K}$ with the bias voltage maintained at $0 \mathrm{~V}$. The interface trap state density and time constant were deduced using an analysis of the frequency dispersion in capacitance and conductance data. They established a traps state model with two levels of traps at the AlGaN/GaN interface and one level located in the barrier AlGaN surface with reported trap state values of $10^{12} \mathrm{~cm}^{-2} \mathrm{eV}^{-1}$ and a time constant varying between $1 \mu \mathrm{s}$ and $3 \mathrm{~ms}$.

Kordos et al. [20] published the frequency dependent conductance measurement results and the effect of annealing on the trap states in the $\mathrm{Al}_{2} \mathrm{O}_{3} / \mathrm{AlGaN} / \mathrm{GaN}$ MOSHFETs. They had shown that a broadening of the conductance peaks is largely suppressed after the annealing of the gate oxide. They found that the density of traps in the non-annealed devices was in the range of $10^{11} \mathrm{~cm}^{-2} \mathrm{eV}^{-1}$ and it was slightly decreased after annealing.

In another study, the results of the trap states investigation in the $\mathrm{AlGaN} / \mathrm{GaN}$ HEMTs and $\mathrm{Al}_{2} \mathrm{O}_{3} / \mathrm{AlGaN} / \mathrm{GaN}$ MOS-HEMTs obtained by using the dynamic capacitance dispersion technique were published by Xiao-Hua Ma et al. [17]. They calculated trap state densities for the $\mathrm{Al}_{2} \mathrm{O}_{3} / \mathrm{AlGaN}$ interface as $1.4 \times 10^{13} \mathrm{eV}^{-1} \mathrm{~cm}^{-2}$ and approx. twofold higher values for the surface traps density at the Schottky/AlGaN interface (AlGaN surface).

In our previous study [18], we presented a study on the surface trap states investigation in unpassivated and $\mathrm{SiN}_{\mathrm{x}}$ passivated $\mathrm{Al}_{0.83} \mathrm{In}_{0.17} \mathrm{~N} /$ AlN/GaN heterostructures using admittance methods. We found values of $(4-13) \times 10^{12} \mathrm{eV}^{-1} \mathrm{~cm}^{-2}$ and (3-7) $\mu$ s for the surface trap states densities and time constants in the unpassivated $\mathrm{Al}_{0.83} \mathrm{In}_{0.17} \mathrm{~N} / \mathrm{AlN} / \mathrm{GaN}$ heterostructures, respectively. The $\mathrm{SiN}_{\mathrm{x}}$ passivation on the $\mathrm{Al}_{0.83} \mathrm{In}_{0.17} \mathrm{~N} / \mathrm{AlN} / \mathrm{GaN}$ HEMT decreased the surface state density to the $1.5 \times 10^{12} \mathrm{eV}^{-1} \mathrm{~cm}^{-2}$.

Up to now, there are no reports about the identification of the trapping effects in AlInGaN/GaN heterostructures. In the present paper, we have investigated the electrical parameters of the Ni/Au Schottky contacts on the AlInGaN/GaN heterostructures from the experimental forward bias current-voltage $(I-V)$ characteristics at a temperature of $300 \mathrm{~K}$. The capacitance-voltage $(C-V)$, conductance-voltage $(G / \omega-V)$ measurements were done at various frequencies $(5 \mathrm{kHz}-5 \mathrm{MHz})$. Frequency dependent dispersion of the admittance was analyzed using an equivalent circuit model and the energy densities and relaxation time constants of the trap states were calculated.

\section{Experimental procedure}

A low-pressure metalorganic chemical vapor deposition (MOCVD) reactor (Aixtron 200/4 HT-S) was used for the growth process of the $\mathrm{Al}_{\mathrm{x}} \mathrm{In}_{\mathrm{y}} \mathrm{Ga}_{1-\mathrm{x}-\mathrm{y}} \mathrm{N} / \mathrm{GaN}$ heterostructures. The trimethylaluminum (TMAl), trimethylindium (TMIn), triethylgallium (TEGa), and ammonia precursors were used as $\mathrm{Al}, \mathrm{In}, \mathrm{Ga}$, and $\mathrm{N}$ source, respectively. In the beginning of the growth process, the surface of the c-plane (0001) singlepolished 2" diameter sapphire $\left(\mathrm{Al}_{2} \mathrm{O}_{3}\right)$ substrate was baked under $\mathrm{H}_{2}$ ambient at $1250^{\circ} \mathrm{C}$ for $12 \mathrm{~min}$. After the baking process, the growth was continued with the growth of a nominally $50 \mathrm{~nm}$ thick, low-temperature $\left(515^{\circ} \mathrm{C}\right.$ and $\left.100 \mathrm{mbar}\right) \mathrm{GaN}$ nucleation layer and the nominally 
$3 \mu \mathrm{m}$ thick unintentionally doped (UID) GaN template layer grown at $1040^{\circ} \mathrm{C}$ and 300 mbar pressures conditions. The $\mathrm{GaN}$ template layer was followed by $118 \mathrm{~nm}$ thick UID $\mathrm{Al}_{\mathrm{x}} \mathrm{In}_{\mathrm{y}} \mathrm{Ga}_{1-\mathrm{x}-\mathrm{y}} \mathrm{N}$ quaternary epilayers that were grown at a temperature of $1150^{\circ} \mathrm{C}$ and $30 \mathrm{mbar}$ (Fig. 1a). The atomic ratio of the indium and the aluminum in $\mathrm{Al}_{\mathrm{x}} \mathrm{In}_{\mathrm{y}} \mathrm{Ga}_{1-\mathrm{x}-\mathrm{y}} \mathrm{N}$ epilayers were determined using X-ray Photoelectron Spectroscopy (XPS) and X-ray diffraction (XRD) methods.

The spectra reveal a (0002) plane peak of the GaN layer at $34.913^{\circ}$. Besides the (0002) diffraction peak of $\mathrm{GaN}$, the diffraction from $\mathrm{Al}_{\mathrm{x}} \mathrm{In}_{\mathrm{y}} \mathrm{Ga}_{1-\mathrm{x}-\mathrm{y}} \mathrm{N}$ epilayers was also observed at a higher angle side of $\mathrm{GaN}$ (0002) diffraction peak at the $35.923^{\circ}$. The rocking curve ( $\omega$-scan) of the (0002) symmetric and (10-12) asymmetric plane were done for the $\mathrm{Al}_{\mathrm{x}} \mathrm{In}_{\mathrm{y}} \mathrm{Ga}_{1-\mathrm{x}-\mathrm{y}} \mathrm{N}$ epilayers. The full width at half maximum (FWHM) values of X-ray rocking curve are 269 arcsec and 327 arcsec for the (0002) and (10-12) plane, respectively.

The $\mathrm{Al}$ and In compositions have been determined by the fitting of $2 \theta$-scans at an AlInGaN (0002) diffraction pattern using the Global Fit software. The $\mathrm{Al}, \mathrm{In}$, and $\mathrm{Ga}$ incorporations of the sample have been approximately found to be $84 \%(\mathrm{Al}), 13 \%(\mathrm{In})$, and $3 \%(\mathrm{Ga})$, respectively. XPS measurement has been used to confirm the $\mathrm{Al}$ and In content in the AlInGaN layers.

After the determination of the Al, In, and Ga ratio in the AlInGaN layer, the wafers were cut into several piece of $7 \times 7 \mathrm{~mm}$ for ohmic and Schottky contact fabrication. Prior to the contact formation, samples were cleaned with acetone in an ultrasonic bath and then treated with isopropyl alcohol and rinsed in deionized (DI) water that had $18 \mathrm{M} \Omega$ resistivity. After DI rinsing, in order to remove the surface oxides, the sample was dipped in $\mathrm{HCl}: \mathrm{H}_{2} \mathrm{O}(1: 1)$ solution for $30 \mathrm{~s}$ and then rinsed in DI water again for a prolonged period.

After sample cleaning, the process was continued with metallization, the $\mathrm{Ti} / \mathrm{Al} / \mathrm{Ni} / \mathrm{Au}(45 / 120 / 55 / 300 \mathrm{~nm})$ metals were deposited on the AlInGaN surface in square Van Der Pauw geometry under a vacuum of $10^{-7}$ Torr (Fig. 1b). In order to form ohmic contacts, samples were annealed at $800^{\circ} \mathrm{C}$ for $45 \mathrm{~s}$ in $\mathrm{N}_{2}$ ambient. After the formation of ohmic contacts, $1 \mathrm{~mm}$ diameter circular dot Schottky contacts were formed by the evaporation of $40 \mathrm{~nm} \mathrm{Ni}$ and $250 \mathrm{~nm}$ Au metals one after another under a vacuum of $10^{-7}$ Torr (Fig. 1b).

The current-voltage $(I-V)$ characteristics were measured with a Keithley model $199 \mathrm{dmm} /$ scanner. The capacitance-voltage $(C-V)$ and conductance-voltage $(G / \omega-V)$ measurements were performed by the use of an HP 4192A LF impedance analyzer in the frequency range of $5 \mathrm{kHz}-5 \mathrm{MHz}$. An AC signal was attenuated to amplitude of $50 \mathrm{mV}_{\mathrm{rms}}$ in order to meet the small signal requirement. All of the measurements of $I-V, C-V$, and $G / \omega-V$ were done at a temperature of $300 \mathrm{~K}$. The carrier mobility and the carrier density were measured using low magnetic field $(0.5 \mathrm{~T})$ Hall Measurement System between the temperature ranges of 12 and $300 \mathrm{~K}$.

\section{Results and discussions}

\subsection{Current-voltage (I-V) measurements}

The carrier density and the mobility of quaternary AlInGaN alloy were determined using low magnetic field Hall measurements. The mobility and carrier density results were calculated between 12 and $300 \mathrm{~K}$ at a magnetic field of $0.5 \mathrm{~T}$ using standard square Van der Pauw geometry. The mobility and carrier density versus temperature curves was given in Fig. 2. The negative Hall voltage sign showed that the current conductions in the unintentionally doped quaternary $\mathrm{Al}_{0.84} \mathrm{In}_{0.13} \mathrm{Ga}_{0.03} \mathrm{~N}$ epilayer is determined by n-type carriers.

As can seen from Fig. 2, the Hall mobility for $\mathrm{Al}_{0.84} \mathrm{In}_{0.13} \mathrm{Ga}_{0.03} \mathrm{~N}$ / GaN heterostructures sample increases from $883 \mathrm{~cm}^{2} \mathrm{~V}^{-1} \mathrm{~s}^{-1}$ at $300 \mathrm{~K}$ to values $458 \mathrm{~cm}^{2} \mathrm{~V}^{-1} \mathrm{~s}^{-1}$ at $12 \mathrm{~K}$. From Fig. 2, it can be seen that, the mobility values increase with decreasing temperature from room temperature to the $12 \mathrm{~K}$, but shows leveling out at low temperatures. This behavior provides that the n-type carriers in the channel between the

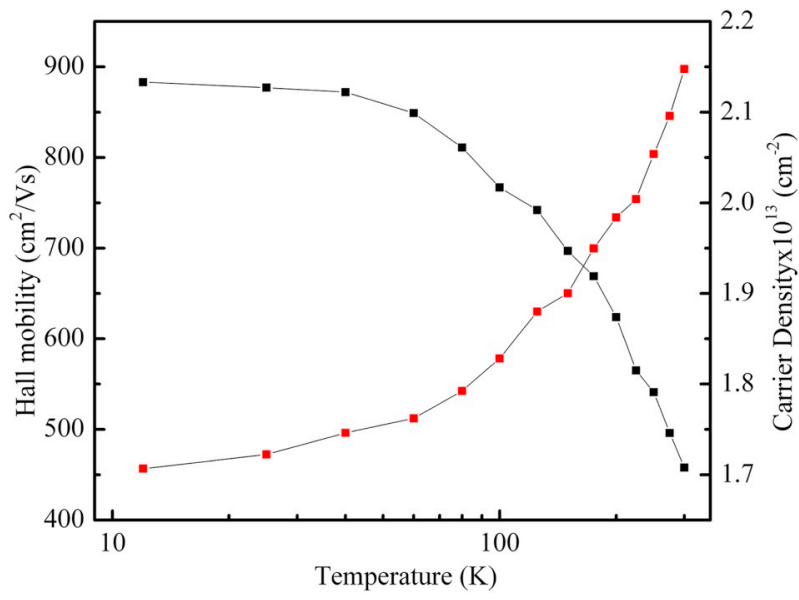

Fig. 2. Hall mobility and carrier density versus temperature behavior for the $\mathrm{Al}_{0.84} \mathrm{In}_{0.13} \mathrm{Ga}_{0.03} \mathrm{~N} / \mathrm{GaN}$ heterostructure.

AlInGaN layer and GaN layer shows 2-dimensional (2D) character. The electron concentration calculated as $1.7 \times 10^{13} \mathrm{~cm}^{-2}$ at $12 \mathrm{~K}$ and increases monotonically with increasing temperature and approaches to values of $2.15 \times 10^{13} \mathrm{~cm}^{-2}$ at $300 \mathrm{~K}$.

In Fig. 3, we show the forward and reverse bias $\ln I$ vs. $V$ characteristics of the Ni/Au Schottky contacts on the AlInGaN/GaN heterostructures measured at $300 \mathrm{~K}$. The measured currents at forward and reverse bias voltages of $\pm 2 \mathrm{~V}$ showed a large rectification ratio of 7878 , indicating that good Schottky contact could be fabricated on AlInGaN quaternary alloy using Ni metal. The reverse bias current saturates nearly at the reverse bias voltage value of $-9.5 \mathrm{~V}$. For this reason, typically saturation of the current which occurs when 2DEG is depleted cannot be seen in the investigated range.

In Schottky contacts, the ideality factor $(n)$, zero bias Schottky barrier height $(\mathrm{SBH})\left(\Phi_{\mathrm{BO}}\right)$, series resistance $\left(R_{\mathrm{S}}\right)$, and Richardson constant $\left(\mathrm{A}^{*}\right)$ parameter dependent to the contact and material properties which govern current transport by the thermionic emission (TE) model [26]. It is possible to extract the values of this parameter from analyzing current versus voltage curves [26].

The TE model gives the relationship between $I$ and $V$ can be expressed with an equation given below [26];

$I=I_{S}\left[\exp \left(\frac{q\left(V-I R_{S}\right)}{n k T}\right)-1\right]$

$I_{S}=A A^{*} T^{2} \exp \left(-\frac{q \Phi_{B 0}}{k T}\right)$

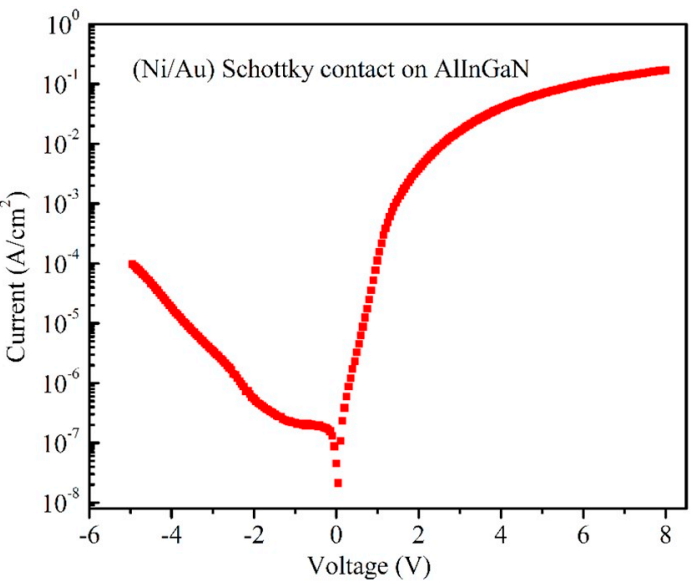

Fig. 3. The forward and reverse-bias current-voltage characteristics of the $\mathrm{Ni}$ / Au Schottky contacts on the AlInGaN/GaN heterostructures measured at $300 \mathrm{~K}$. 
In the Eq. (1), $A^{*}$ were calculated using the $A^{*}=4 \pi m^{*} q k^{2} / h^{3}$ relation, where $m^{*}$ is the effective electron mass for the quaternary $\mathrm{Al}_{0.84} \mathrm{In}_{0.13} \mathrm{Ga}_{0.03} \mathrm{~N}$ epitaxial layer and were estimated that $m^{*}=0.36 m_{0}$ by a linear extrapolation from the measured values of AlN, InN, and GaN [27]. Thus, the Richardson constant can be calculated to be $42.8 \mathrm{Acm}^{-2} \mathrm{~K}^{-2}$. The $q, k$ and $h$ are the parameters given in formula that defined for $A^{*}$ and named as electron charge, Boltzman constant and Planck constant, respectively. The other terms in Eq. (1) of $T$ and $A$ is the temperature in Kelvin and contact area, respectively [26].

The contact parameters of $I_{\mathrm{s}}, \Phi_{\mathrm{B} 0}$, and $n$ can be calculated by the linear fitting of the $\ln I$ vs $V$ plots. The $I_{\mathrm{s}}$ saturation current value was extracted by extrapolating the straight line of $\ln I$ to intercept the axis at zero voltage. After the calculation of the $I_{\mathrm{s}}$, the $\Phi_{\mathrm{B} 0}$ parameters can be obtained using Eq. (2).

The parameter of $n$ is generally used to measure the deviation of practical diodes from the ideal thermionic emission model. In the ideal thermionic emission model, $n$ values have been taken as 1 . However, in some cases, the $n$ values may be higher than 1 , in which case different current mechanisms must be investigated. For example, thermionic field emission and tunneling mechanisms can be the current-transport of the Schottky contacts on the AlInGaN quaternary alloy [25,26,29]. The $n$ value was calculated from the slope of the linear region of the $\ln I-$ $V$ plot given in Fig. 4(a) using Eq. (3) [26].

$n=\frac{q}{k T}\left(\frac{\partial V}{\partial(\ln I)}\right)$

The least square fitting was performed in the linear region of experimental data on the $\ln I-V$ plot as seen in Fig. 4(a). The value of $n, I_{\mathrm{s}}$, were determined from the slope and the y-axis intercept of the fitted straight line. The $n, I_{\mathrm{s}}$ and $\Phi_{\mathrm{B} 0}$ were determined as 5.6, $9.5 \times 10^{-10}$ and $0.80 \mathrm{eV}$, respectively, at a temperature of $300 \mathrm{~K}$. The value found for $n$ in the calculation result is higher than 1 . This means that there may be trap centers that set the tunneling current at the contact point [25,26,29].

The TE model works for the zero or low $R_{\mathrm{s}}$ which can be neglected in the low forward region of $I-V$ curve. However, $R_{\mathrm{s}}$ influences the electrical characteristics of the Schottky contact so we used the Cheung method as an efficient method to evaluate $R_{s}$. The forward bias $I-V$ characteristics due to the thermionic emission model of a Schottky contact with $R_{\mathrm{S}}$ can be expressed as Cheung's functions given below [28];

$\frac{d V}{d \ln I}=n \frac{k T}{q}+I R_{S}$
As given in Fig. 4(b), the $d V / d \ln I$ vs. $I$ plot of measured $I-V$ characteristics of $\mathrm{Ni} / \mathrm{Au}$ Schottky contact on AlInGaN/GaN heterostructures at the temperature of $300 \mathrm{~K}$ is given in a straight line. According to Eq. (4), its slope and y-axis intercept will give a determination of $n$ and $R_{\mathrm{S}}$ values. The $n$ and $R_{\mathrm{s}}$ values were obtained as 17.4 and $3231 \Omega$, respectively. Because of $R_{\mathrm{s}}$ effects, we obtained higher $n$ values from Cheung's function than when calculated using Eq. (3).

\subsection{Capacitance-voltage $(C-V)$ and conductance-voltage $(G / \omega-V)$ measurements}

The capacitance-voltage $\left(C_{m}-V\right)$ and conductance-voltage $\left(G_{m} / \omega\right.$-V) measurements were done between the frequency of $5 \mathrm{kHz}$ and $5 \mathrm{MHz}$, at room temperature, for $\mathrm{Ni} / \mathrm{Au}$ Schottky contact on the AlInGaN/GaN heterostructures, as shown in Fig. 5(a) and (b), respectively. The DC bias voltage was swept from -8.5 to $+0.5 \mathrm{~V}$. Featuring one capacitance plateaus around $-1.5 \mathrm{~V}$ along with one sharp transition from accumulation to the depletion region (nearly from -2.5 to $-7 \mathrm{~V}$ ).

Also, the strong dispersions in the capacitance curves at the accumulation regions (around $-1.5 \mathrm{~V}$ ) can be seen when looking the Fig. 5(a). The frequency dispersion of the admittance curves strongly depends on the external bias at low-frequency, while a change in capacitance at high-frequency becomes very small. This behavior can be attributed to the surface trap sates between the metal-AlInGaN layers. In addition, there is strong frequency dispersion at the sharp transition regions (depletion region) that became significant, which was reflecting that there are interface trap states between the AlInGaN and GaN layer. Furthermore, sharp peaks, the position of this peak strongly depends on the bias voltage, in the beginning of the accumulation regions (at $-3.3 \mathrm{~V}$ for the frequency of $5 \mathrm{kHz}$ ) of the measured $C-V$ curve at low frequency values were detected [11-14,16,18-20,30].

On the other hand, these peaks disappeared between the frequencies of $30 \mathrm{kHz}$ and $5 \mathrm{MHz}$ and that is shows that there is a considerable amount of traps between the AlInGaN quaternary layer and GaN layer interfaces. These results indicated that the measured $C-V$ curves contain the total effect of the interface trap states and the effect of the surface trap states in the Ni/Au Schottky contact on the AlInGaN/GaN heterostructures. At lower frequencies, the trap states (interface and surface trap) can follow the A.C. signal and yield an excess capacitance that depends on the frequency. However, in the high-frequency case, the trap states cannot follow the AC signal and consequently do not contribute appreciably to the capacitance $[14,15]$.

In the $\mathrm{Al}_{0.84} \mathrm{In}_{0.13} \mathrm{Ga}_{0.03} \mathrm{~N} / \mathrm{GaN}$ heterostructure, the $\mathrm{Al}_{0.84} \mathrm{In}_{0.13} \mathrm{Ga}_{0.03} \mathrm{~N}$ barrier layer has a very high energy band gap
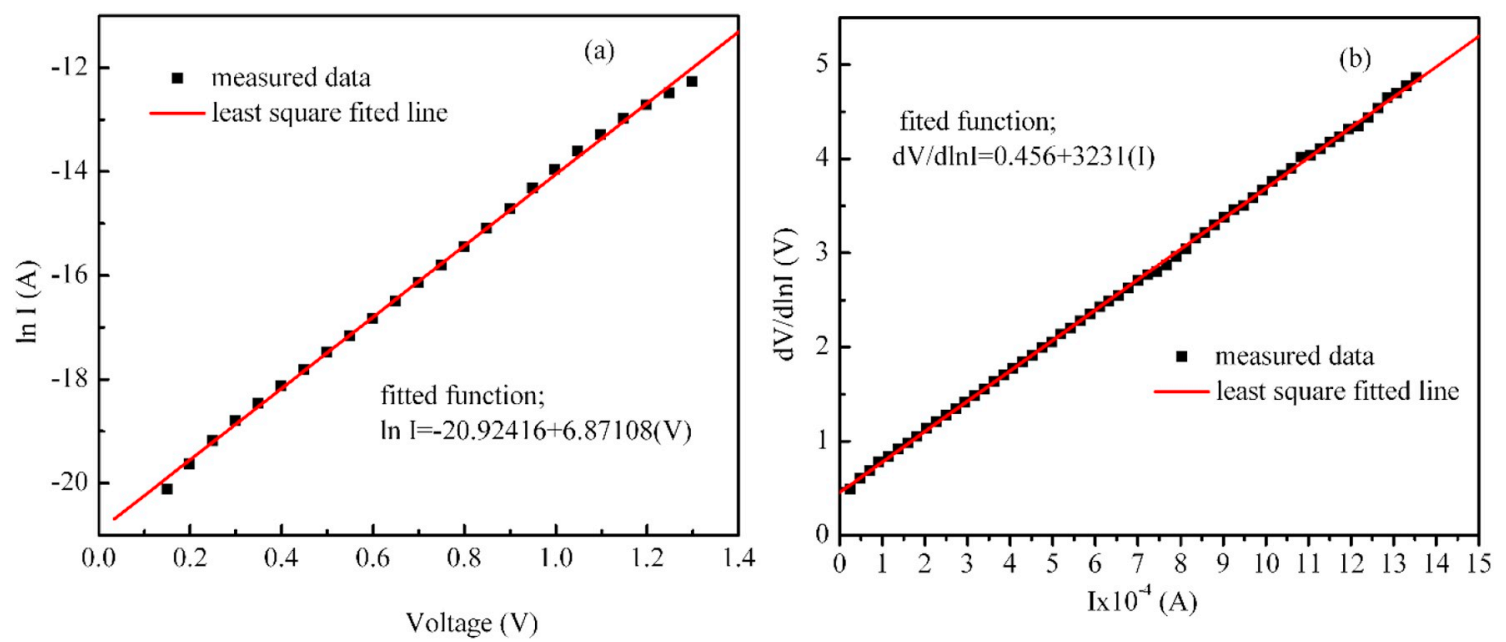

Fig. 4. (a) $\ln I-V$ vs. $I$ and (b) $\mathrm{d} V / \mathrm{dln} I$ vs. $I$ plot of the Ni/Au Schottky contacts on the AlInGaN/GaN heterostructures measurement. The line is the least square fit of the linear function to the experimental data. 

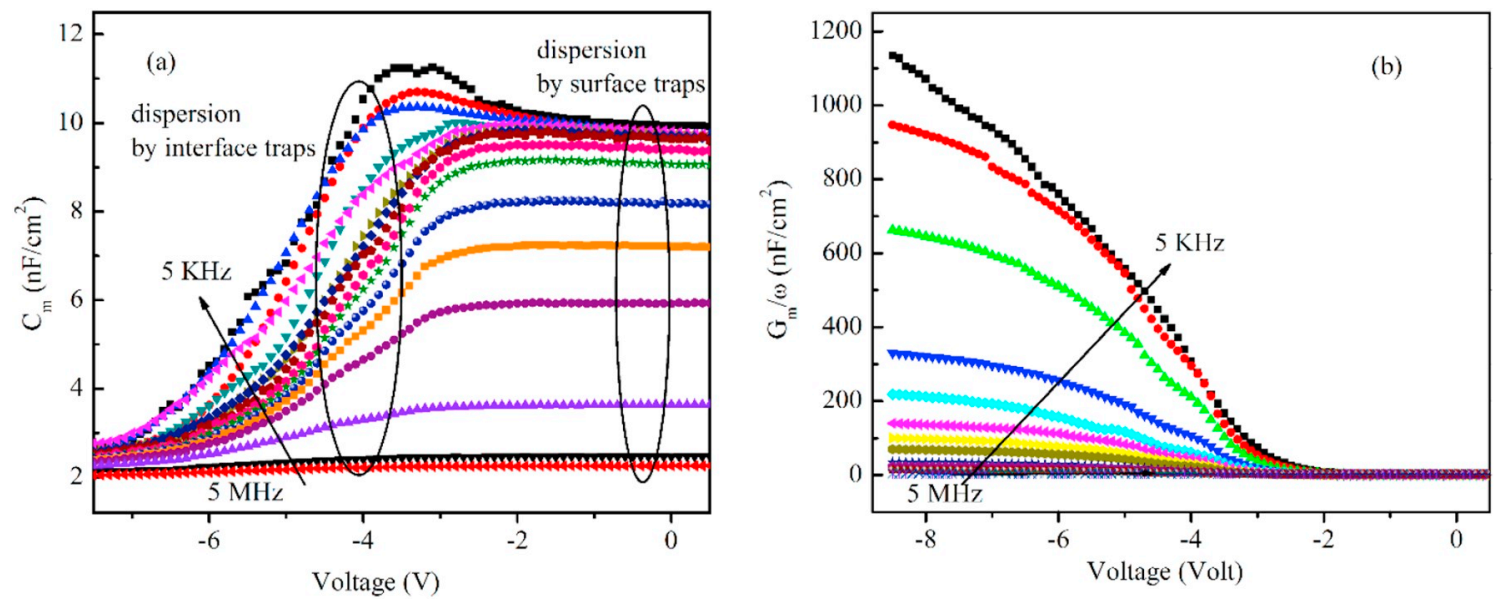

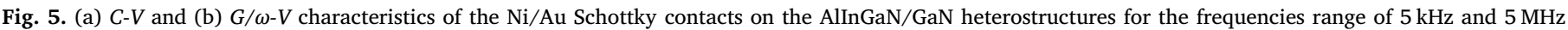
measured at $300 \mathrm{~K}$.

$(\approx 5.4 \mathrm{eV})$ and a metal-AlInGaN/GaN structure can be treated as a MS capacitor. Under a large reverse bias voltage, the capacitance is small and the corresponding boundary of the depletion layer is in the GaN template layer. As the reverse voltage decreases, a capacitance plateau appears, corresponding to the depletion of the two dimensional electron gas (2DEG) located at the 2DEG channel $\left(\mathrm{Al}_{0.84} \mathrm{In}_{0.13} \mathrm{Ga}_{0.03} \mathrm{~N} / \mathrm{GaN}\right.$ interface). Further decrements in the voltage cause a new transition region, wherein the capacitance increases rapidly with decreasing reverse voltage. Moreover, another sharp capacitance slope appears on the right side of the plateau, which indicates that the depletion layer is in the AlInGaN layer. The interface and surface trap states on the AlInGaN/GaN interface and between metal-AlInGaN interface (surface state) cause a deviation between both of the curves.

The capacitance of an ideal Schottky contact on the AlInGaN/GaN heterostructures contains AlInGaN barier layer $\left(C_{\mathrm{AlInGaN}}\right)$ and the capacitance of the depletion region of $\mathrm{GaN}$ template layer $\left(C_{\mathrm{GaN}}\right)$. Despite the AlInGaN quaternary alloy having strong potential for applications in optoelectronic devices, the development of high quality AlInGaN epilayer is still a challenging task due to the phase separation, alloy fluctuations, large thermodynamic miscibility gap of the binary compound and differences in the lattice constants of the binary compounds (AlN, GaN, and InN) [31]. Moreover, the composition pulling effects and strain in the epilayer become dominant with increasing epilayer thickness. The compositional non-uniformity in the AlInGaN barrier layer that is caused by alloy segregation and V-shaped pits in the surface morphologies can generate a considerable amount of trap states at the AlInGaN/GaN interface. The electrical behavior of the interface trap states (between AlInGaN and GaN layer) can be modeled as capacitive $\left(C_{\mathrm{it}}\right)$ and associated resistance terms for the traps $\left(R_{\mathrm{it}}\right)$ component in parallel connection with the GaN depletion region capacitor $\left(C_{\mathrm{GaN}}\right)$. In addition to the interface trap states, surface states are present at any metal-semiconductor interface and it can be modeled as surface-traprelated resistance $\left(R_{\text {surf }}\right)$ and capacitance $\left(C_{\text {surf }}\right)[15,18,30]$. Both of the interfaces trap states and surface trap states can be modeled as a serial combination of the $R_{\mathrm{st}}$ and $R_{\mathrm{it}}$ and capacitance of $C_{\mathrm{it}}$ and $C_{\mathrm{st}}$ in parallel connection with the AlInGaN barrier layer $\left(C_{\mathrm{AlInGaN}}\right)$. The equivalent circuit model of a Schottky contacts on AlInGaN/GaN heterostructures were used by taking into account the effect of the interface trap state between the AlInGaN and GaN interface and surface trap states present at the metal-AlInGaN layer. Furthermore, in addition to the interface and surface traps, there might also be traps that are related to the crystal defects such as point defects (vacancies, interstitials and substitutional atoms), line defects (dislocations), planar defects (grain boundaries, stacking faults, twins and inversion domain boundaries) or volume defects (voids, cracks and nanopipes) within the bulk GaN and/ or AlInGaN layers [32]. However, the bulk states are deep below the conduction band edge and have time constants as large as milliseconds, and their effects could not observable with admittance methods [30]. For these reasons, the bulk states were not considered in this analysis.

Bias-and frequency-dependent capacitance and conductance measurements were carried out simultaneously, assuming a parallel combination of $C_{\mathrm{m}}$ and $G_{\mathrm{m}}$. In these studies, the equivalent circuit, which includes the total effects of the trap states (interface and surface traps), were used to analyze the location with respect to the conduction band edge, distribution, and relaxation time of trap states in $(\mathrm{Ni} / \mathrm{Au})$ AlInGaN/GaN heterostructures. The parallel capacitance $\left(C_{\mathrm{p}}\right)$ and conductance $\left(G_{\mathrm{p}} / \omega\right)$ can be obtained from measured $C_{\mathrm{m}}, G_{\mathrm{m}} / \omega$ curves and calculated $R_{\mathrm{s}}$ values using equations given below [14,15,18];

$$
C_{p}=\frac{-C_{b}\left[\left(C_{m}^{2}-C_{m} C_{b}\right) \omega^{2}+G_{m}^{2}\right]}{\omega^{4} C_{m}^{2} C_{b}^{2} R_{s}^{2}+\omega^{2}\left(C_{b}^{2} R_{s}^{2} G_{m}^{2}+C_{m}^{2}+C_{b}^{2}-2 C_{b}^{2} R_{s} G_{m}-2 C_{m} C_{b}\right)+G_{m}^{2}}
$$

$$
\frac{G_{p}}{\omega}=\frac{-\omega C_{b}^{2}\left(R_{s} C_{m}^{2} \omega^{2}+R_{s} G_{m}^{2}-G_{m}\right)}{\omega^{4} C_{m}^{2} C_{b}^{2} R_{s}^{2}+\omega^{2}\left(C_{b}^{2} R_{s}^{2} G_{m}^{2}+C_{m}^{2}+C_{b}^{2}-2 C_{b}^{2} R_{s} G_{m}-2 C_{m} C_{b}\right)+G_{m}^{2}}
$$

In Eqs. (5a) and (5b), $\omega=2 \pi f$ is the radial frequency. The barrier capacitance $\left(C_{b}\right)$, in Eqs. (5a) and (5b), was taken as the capacitance of the AlInGaN layer and the value was determined from the plateau in the $C-V$ curve associated with the accumulation of electrons in the twodimensional electron gas channel. It is a value taken as $8 \mathrm{pF}$ that is measured at zero-bias voltage and at $5 \mathrm{kHz}$. The $R_{s}$ parameter in Eqs. (4), (5a) and (5b) is the series resistance of the Schottky contact on the AlInGaN/GaN heterostructures and the values calculated as $3231 \Omega$ using a method developed by Cheung and Cheung given in Eq. (4).

The trap (interface + surface trap) states density $\left(D_{\mathrm{ts}}\right)$ and relaxation times of those states $\left(\tau_{\mathrm{ts}}\right)$ can be extracted by fitting the equations derived by AC analysis to the $C_{p}-\omega$ and $G_{\mathrm{p}} / \omega$ - $\ln \omega$ curves. The equivalent parallel capacitance $C_{\mathrm{p}}$ and conductance $G_{\mathrm{p}} / \omega$ as functions of frequency, by assuming a continuum of trap levels, can be expressed as $[11,18,20]$;

$C_{p}=C_{\text {barier }}+\frac{q D_{t s}}{\omega \tau_{t s} \tan \left(\omega \tau_{t s}\right)}$

$\frac{G_{p}}{\omega}=\frac{q D_{t s}}{2 \omega \tau_{t s}} \ln \left(1+\omega^{2} \tau_{t s}^{2}\right)$

The calculated $G_{p} / \omega$ vs. $\ln (\omega)$ curves using Eq. (5b) for the Ni/Au Schottky contact on the AlInGaN/GaN heterostructure for a different bias voltage are given in Fig. 6 . The $G_{p} / \omega$ - $\ln (\omega)$ curves gives a peak for each bias voltage values due to the $D_{\text {ts }}$ contribution. It can be clearly seen that the peak amplitude of $G_{p} / \omega$ increases and the peak position 


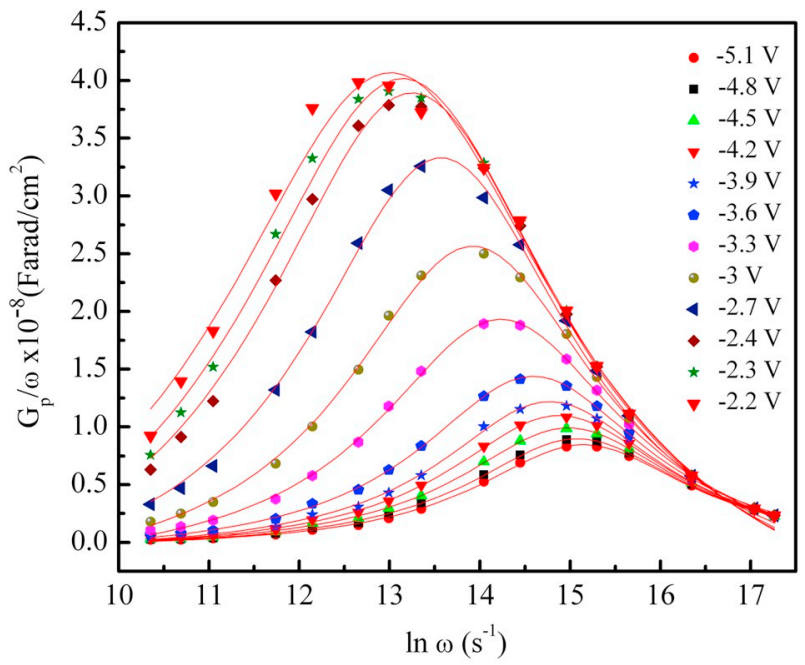

Fig. 6. Conductance versus radial frequency of the Ni/Au Schottky contacts on the AlInGaN/GaN heterostructures calculated from measured data for selected gate voltages. The solid lines are the best fit of Eq. (6b) to the experimental data.

shifts to lower frequency values when the bias voltage is varied from $-5.1 \mathrm{~V}$ to $-2.2 \mathrm{~V}$ values. The only one peak is clearly visible in the $G_{p} /$ $\omega$ curves in Fig. 6 for each voltage values. The radial frequency values of peak position, for each voltage values, changed between $3 \times 10^{6} \mathrm{~s}^{-1}$ and $4 \times 10^{5} \mathrm{~s}^{-1}$. The obtained radials frequency interval, at which peaks appear, indicates that only fast trap states were measured in InAlGaN/GaN heterostructures.

The $D_{\text {ts }}$ and $\tau_{\text {ts }}$ were calculated by fitting the Eq. (6b) to the experimental $G_{\mathrm{p}} / \omega$ vs. $\ln (\omega)$ curves. The $D_{\mathrm{ts}}$ and $\tau_{\mathrm{ts}}$ parameters as a function of the energy difference between the conduction band edge $\left(E_{\mathrm{c}}\right)$ and the trap states energy $\left(E_{\mathrm{ts}}\right)$ can be calculated using the Equations given in the references $[14,15]$. The $D_{\text {ts }}$ and $\tau_{\text {ts }}$ values as a function of energy separation from the conduction-band edge $\left(E_{\mathrm{c}}-E_{\mathrm{ts}}\right)$ were given in Fig. 7. The obtained $D_{\text {ts }}$ values change between $1.3 \times 10^{11} \mathrm{eV}^{-1} \mathrm{~cm}^{-2}$ and $6.2 \times 10^{11} \mathrm{eV}^{-1} \mathrm{~cm}^{-2}$. On the other hand, the values found for the $\tau_{\text {ts }}$ vary between $4.8 \mu \mathrm{s}$ and $5.3 \mu$ s intervals. The measured $\tau$ values confirm that in InAlGaN/GaN heterostructures only fast trap states were detected. However, in literature they reported results for trap states investigation in $\mathrm{AlGaN} / \mathrm{GaN}$ (HFETs), $\mathrm{SiO}_{2}$ / $\mathrm{AlGaN} / \mathrm{GaN}$ as well as $\mathrm{Al}_{2} \mathrm{O}_{3} / \mathrm{AlGaN} / \mathrm{GaN} / \mathrm{Si}$ (MOSHFETs) where both slow and fast tarps states have been observed $[11,23]$.

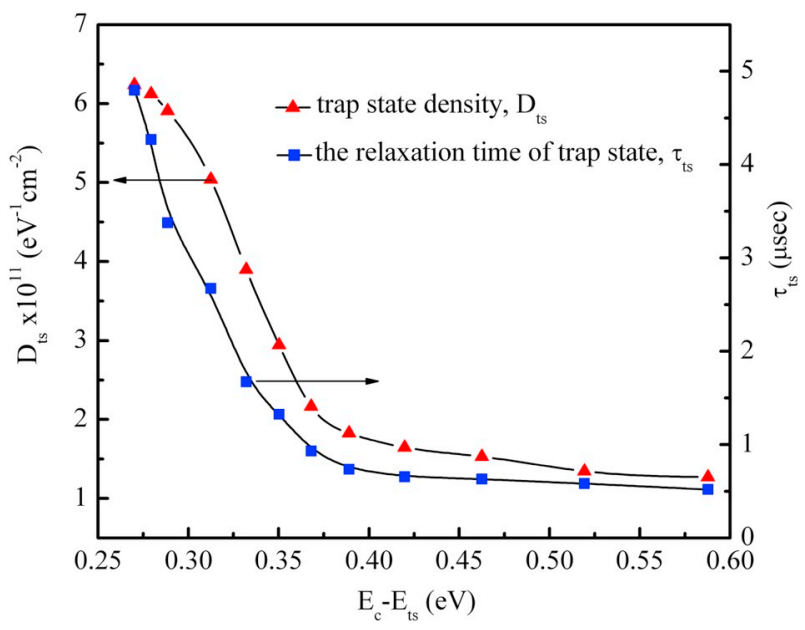

Fig. 7. Extracted densities and the relaxation time of the trap states in the AlInGaN/GaN heterostructures as a function of conduction band edge. The line is given for eye guide.
The obtained $D_{\text {ts }}$ values for the $(\mathrm{Ni} / \mathrm{Au})$ Schottky contacts on AlInGaN/GaN heterostructures are one or two orders of magnitude smaller than the other published values for trap states density in $\mathrm{AlGaN} / \mathrm{GaN}$ and AlInN/GaN heterostructures. For example, we calculated the values of $(4-13) \times 10^{12} \mathrm{eV}^{-1} \mathrm{~cm}^{-2}$ and $(3-7) \mu \mathrm{s}$ for the surface trap states densities and time constants in the $\mathrm{Al}_{0.83} \mathrm{In}_{0.17} \mathrm{~N} /$ AlN/GaN heterostructures, respectively, and the surface state density decreased to a value of $1.5 \times 10^{12} \mathrm{eV}^{-1} \mathrm{~cm}^{-2}$ by $\operatorname{SiN}_{\mathrm{x}}$ passivation [18]. Xiao-Hua Ma et al. [17] reported trap state density values for the $\mathrm{Al}_{2} \mathrm{O}_{3} / \mathrm{AlGaN}$ interface as $1.4 \times 10^{13} \mathrm{eV}^{-1} \mathrm{~cm}^{-2}$ and about two orders of magnitude higher values for the surface traps density at the Schottky/AlGaN interface (AlGaN surface). The $(1.02-4.67) \times 10^{13} \mathrm{eV}^{-1} \mathrm{~cm}^{-2}$ and $(0.09-0.12) \mu s$ values for the density and time constant of surface states in Schottky-gate on the AlGaN/ GaN HEMTs were published by Zhu et al. [23]. Miller et al. [16] used the various models in order to determine the density and the relaxation time of the trap state in the $\mathrm{AlGaN} / \mathrm{GaN}$ heterostructure field-effect transistor. They found values of $10^{12} \mathrm{eV}^{-1} \mathrm{~cm}^{-2}$ and $1 \mu \mathrm{s}$ for the trap state densities and the relaxation time. However, they could not be determined unambiguously regarding the location of the traps. On the other hand, Chu et al. [30] found higher values $\left(10^{13}-10^{14} \mathrm{eV}^{-1} \mathrm{~cm}^{-2}\right)$ and smaller time constant values $(0.1-1 \mu \mathrm{s})$ for the trap states in the $\mathrm{AlGaN} / \mathrm{GaN}$ heterostructures. Stoklass et al. [11] exposed two different types of trap sates, slow ( $8 \mathrm{~ms})$ and fast $(0.1-1 \mu \mathrm{s})$, which are in the $\mathrm{AlGaN} / \mathrm{GaN}$ (HFETs) as well as MOSHFETs. They attributed the slow traps to the surface states and they assumed that the fast traps were related to the bulk states. However, we attributed the measured trap states in the $(\mathrm{Ni} / \mathrm{Au})$ Schottky contact on the AlInGaN/GaN heterostructures as the total of the surface state between the $\mathrm{Ni} / \mathrm{Au}$ contact and AlInGaN layer and the interface state between the AlInGaN layer and GaN layer. The external bias and frequency dependent dispersion in the deep accumulation regime (at zero or near very small reverse voltage) indicates that there are surface trap states between the metalAlInGaN layers, and the frequency dispersion at sharp transition regions became significant, which reflected that there are interface trap states between the AlInGaN and GaN layer.

\section{Conclusion}

The trap states in the AlInGaN/GaN Schottky contact (HEMTs) were investigated using frequency-dependent capacitance and conductance measurements. The measured $C-V-f$ curves contain frequency dependent dispersion in the deep accumulation regime (at zero or near very small reverse voltage) as well as dispersion at the sharp transition regions. This indicates that there are trap states (surface trap states) between the metal-AlInGaN layers and interface trap states between the AlInGaN and $\mathrm{GaN}$ layer. The $C-V$ data show that both metal$\mathrm{Al}_{0.84} \mathrm{In}_{0.13} \mathrm{Ga}_{0.03} \mathrm{~N} / \mathrm{GaN}$ surfaces trap states and the $\mathrm{Al}_{0.84} \mathrm{In}_{0.13} \mathrm{Ga}_{0.03} \mathrm{~N} / \mathrm{GaN}$ interface states are a dominant trapping mechanism in the $5 \mathrm{kHz}-5 \mathrm{MHz}$ frequency range. The equivalent circuit model was used by taking into account the effect of interface trap states surface trap states, and the densities and relaxation times of the trap states were calculated as a function of energy separation from the conduction-band edge. The $D_{t s}$ and $\tau_{t s}$ of the trap states were found as $D_{s t} \cong(1.3-6.2) \times 10^{11} \mathrm{eV}^{-1} \mathrm{~cm}^{-2}$ and $\tau_{s t} \cong(4.8-5.3) \mu \mathrm{s}$, respectively. The obtained $D_{\text {ts }}$ and $\tau_{t s}$ results are one or two orders of magnitude smaller than the other published values for trap states density in $\mathrm{AlGaN} / \mathrm{GaN}$ and AlInN/GaN heterostructures.

\section{Declaration of competing interest}

The authors declare that they have no known competing financial interests or personal relationships that could have appeared to influence the work reported in this paper. 


\section{Acknowledgements}

This work is supported by the TUBITAK under Project No. 116F041. One of the authors (E.O.) also acknowledges partial support from the Turkish Academy of Sciences.

\section{References}

[1] H.P.T. Nguyen, S. Zhang, K. Cui, X. Han, S. Fathololoumi, M. Couillard, G.A. Botton, Z. Mi, p-Type modulation doped InGaN/GaN dot-in-a-wire white-light-emitting diodes monolithically grown on Si(111), Nano Lett. 11 (2011) 1919-1924.

[2] S. Kang, U. Chatterjee, D.-Y. Um, Y.-T. Yu, I.-S. Seo, C.-R. Lee, Ultraviolet-C photodetector fabricated using Si-doped n-AlGaN nanorods grown by MOCVD, ACS Photonics 4 (2017) 2595-2603.

[3] T. Lim, R. Aidam, P. Waltereit, T. Henkel, R. Quay, R. Lozar, T. Maier, L. Kirste, O. Ambacher, GaN-based submicrometer HEMTs with lattice-matched InAlGaN barrier grown by MBE, IEEE Electron Device Lett. 31 (2010) 671-673.

[4] H. Hirayama, Quaternary InAlGaN-based high-efficiency ultraviolet light-emitting diodes, J. Appl. Phys. 97 (2005) 091101.

[5] R. Wang, G. Li, J. Verma, B.S. Rodriguez, T. Fang, J. Guo, Z. Hu, O. Laboutin, Y. Cao, W. Johnson, G. Snider, P. Fay, D. Jena, H. (Grace) Xing, 220-GHz quaternary barrier InAlGaN/AlN/GaN HEMTs, IEEE Electron Device Lett. 32 (2011) $1215-1217$.

[6] F. Lecourt, A. Agboton, N. Ketteniss, H. Behmenburg, N. Defrance, V. Hoel, H. Kalisch, A. Vescan, M. Heuken, J.-C. De Jaeger, Power performance at $40 \mathrm{GHz}$ on quaternary barrier InAlGaN/GaN HEMT, IEEE Electron Device Lett. 34 (2013) 978-980.

[7] N. Ketteniss, L.R. Khoshroo, M. Eickelkamp, M. Heuken, H. Kalisch, R.H. Jansen, A. Vescan, Study on quaternary AlInGaN/GaN HFETs grown on sapphire substrates, Semicond. Sci. Technol. 25 (2010) 75013.

[8] B. Reuters, A. Wille, B. Hollander, E. Sakalauskas, N. Ketteniss, C. Mauder, R. Goldhahn, M. Heuken, H. Kalisch, A. Vescan, Growth studies on quaternary AlInGaN layers for HEMT application, J. Electron. Mater. 41 (2012) 905-909.

[9] B. Reuters, A. Wille, N. Ketteniss, H. Hahn, B. Hollander, M. Heuken, H. Kalisch, A. Vescan, Polarization-engineered enhancement-mode high-electron-mobility transistors using quaternary AlInGaN barrier layers, J. Electron. Mater. 42 (2013) 826-832.

[10] S.C. Binari, K. Ikossi, J.A. Roussos, W. Kruppa, D. Park, H.B. Dietrich, D.D. Koleske, A.E. Wickenden, R.L. Henry, Trapping effects and microwave power performance in AlGaN/GaN HEMTs, IEEE Trans. Electron Dev. 48 (2001) 465-471.

[11] R. Stoklas, D. Gregušová, J. Novák, A. Vescan, P. Kordoš, Investigation of trapping effects in AlGaN/GaN/Si field-effect transistors by frequency dependent capacitance and conductance analysis, Appl. Phys. Lett. 93 (2008) 124103.

[12] H.-A. Shih, M. Kudo, T.-K. Suzuk, Analysis of AlN/AlGaN/GaN metal-insulatorsemiconductor structure by using capacitance-frequency-temperature mapping, Appl. Phys. Lett. 101 (2012) 043501.

[13] J. Werner, K. Ploog, H.J. Queisser, Interface-state measurements at Schottky Contactc: new admittance technique, Phys. Rev. Lett. 57 (1986) 1080-1083.

[14] E.H. Nicollian, A. Goetzberger, The $\mathrm{Si}_{-} \mathrm{SiO}_{2}$ interface - electrical properties as determined by the metal-insulatorsilicon conductance technique, Bell Syst. Tech. J. 46
(1967) 1055-1133

[15] D.K. Schroder, Semiconductor Material and Device Characterization, 3dr ed., Wiley, Hoboken, NJ, 2006.

[16] E.J. Miller, X.Z. Dang, H.H. Wieder, P.M. Asbeck, E.T. Yu, G.J. Sullivan, J.M. Redwing, Trap characterization by gate-drain conductance and capacitance dispersion studies of an $\mathrm{AlGaN} / \mathrm{GaN}$ heterostructure field-effect transistor, J. Appl. Phys. 87 (2000) 8070-8073.

[17] X.-H. Ma, J.-J. Zhu, X.-Y. Liao, T. Yue, W.-W. Chen, Y. Hao, Quantitative characterization of interface traps in $\mathrm{Al} 2 \mathrm{O} 3 / \mathrm{AlGaN} / \mathrm{GaN}$ metal-oxide-semiconductor high-electron-mobility transistors by dynamic capacitance dispersion technique, Appl. Phys. Lett. 103 (2013) 033510.

[18] E. Arslan, S. Bütün, Y. Şafak, E. Özbay, Investigation of trap states in AlInN/AlN/ GaN heterostructures by frequency-dependent admittance analysis, J. Electron. Mater. 39 (2010) 2681-2686.

[19] M. Miczek, C. Mizue, T. Hashizume, B. Adamowicz, Effects of interface states and temperature on the $\mathrm{C}-\mathrm{V}$ behavior of metal/insulator/AlGaN/GaN heterostructure capacitors, J. Appl. Phys. 103 (2008) 104510.

[20] P. Kordoš, R. Stoklas, D. Gregušová, J. Novák, Characterization of AlGaN/GaN metal-oxide-semiconductor field-effect transistors by frequency dependent conductance analysis, Appl. Phys. Lett. 94 (2009) 223512.

[21] W. Huang, T. Khan, T.P. Chow, Comparison of MOS capacitors on n- and p-type GaN, J. Electron. Mater. 35 (2006) 726-732.

[22] K. Zhang, J. Xue, M. Cao, L. Yang, Y. Chen, J. Zhang, X. Ma, Y. Hao, Trap states in InAlN/AlN/GaN-based double-channel high electron mobility transistors, J. Appl. Phys. 113 (2013) 174503.

[23] J.-J. Zhu, X.-H. Ma, B. Hou, W.-W. Chen, Y. Hao, Investigation of trap states in high $\mathrm{Al}$ content $\mathrm{AlGaN} / \mathrm{GaN}$ high electron mobility transistors by frequency dependent capacitance and conductance analysis, AIP Adv. 4 (2014) 037108.

[24] L. Semra, A. Telia, A. Soltani, Trap characterization in AlGaN/GaN HEMT by analyzing frequency dispersion in capacitance and conductance, Surf. Interface Anal. 42 (2010) 799-802.

[25] E. Arslan, S. Bütün, Y. Şafak, H. Çakmak, H. Yu, E. Özbay, Current transport mechanisms and trap state investigations in (Ni/Au)-AlN/GaN Schottky barrier diodes, Microelectron. Reliab. 51 (2011) 576-580.

[26] S.M. Sze, K.K. Ng, Physics of Semiconductor Devices, 3rd ed., John Wiley Sons, Inc., NJ, 2007.

[27] H. Morkoc, Handbook of Nitride Semiconductors and Devices, Vol. 1 Wiley-VCH Verlag GmbH \& Co. KGaA, Weinheim, 978-3-527-40837-5, 2008.

[28] S.K. Cheung, N.V. Cheung, Extraction of Schottky diode parameters from forward current-voltage characteristics, Appl. Phys. Lett. 49 (1986) 85-87.

[29] Engin Arslan, Semsettin Altındal, Süleyman Özçelik, Ekmel Ozbay, Tunneling current via dislocations in Schottky diodes on AlInN/AlN/GaN heterostructures, Semicond. Sci. Technol. 24 (2009) 075003.

[30] R.M. Chu, Y.G. Zhou, K.J. Chen, K.M. Lau, Admittance characterization and analysis of trap states in AlGaN/GaN heterostructures, Phys. Status Solidi C 0 (2003) 2400-2403.

[31] F.F. Krause, J.-P. Ahl, D. Tytko, P.-P. Choi, R. Egoavil, M. Schowalter, T. Mehrtens, K.M. Caspary, J. Verbeeck, D. Raabe, J. Hertkorn, K. Eng, A. Rosenauer, Homogeneity and composition of AlInGaN: a multiprobe nanostructure study, Ultramicroscopy 156 (2015) 29-36.

[32] F.K. Yam, L.L. Low, S.A. Oh, Z. Hassan, P. Predeep (Ed.), Gallium Nitride: An Overview of Structural Defects, Optoelectronics - Materials and Techniques, 2011. 